\title{
ORT_05 - Phenotypic characterization of Pseudomonas aeruginosa as a tracking tool for investigation in a pharmaceutical industry
}

Luiza Vasconcellos ${ }^{1 *}$; Samara Verly da Silva ${ }^{2}$; Luciana Veloso da Costa² ${ }^{2}$ Cristhiane Falavina dos Reis ${ }^{2}$; Joyce Modesto de Andrade²; Josiane Machado Vieira Mattoso²; Igor Barbosa da Silva²; Maria Helena Simões Villas-Boas ${ }^{1}$; Marcelo Luiz Lima Brandão².

${ }^{1}$ Fiocruz/INCQS;

${ }^{2}$ Fiocruz/Bio-Manguinhos.

Introduction: Pseudomonas aeruginosa is an opportunist human pathogen that cannot be present in many products during the production chain of pharmaceuticals.

Objective: The objective of this study was to evaluate the phenotypic profile of $P$. aeruginosa strains as a tool for investigation in a pharmaceutical industry.

Methodology: Ninety P. aeruginosa strains isolated from seven different areas (A-G) from 2014-2020 were evaluated: 40 from active pharmaceutical ingredient (API), 30 from purified water (PWI), 14 from intermediate process solutions (IPS), and six from potable water (PTW). The strains were identified using Vitek ${ }^{\circledR 2}$ with reliability $\geq 93 \%$. The phenotypic profile resulted from 47 biochemical tests were categorized and evaluated with software Bionumerics 8.0. The profiles that presented similarity $\geq 85 \%$ were clustered in the same group. Simpson`s index (SI) was applied to calculate the resolution power of Vitek ${ }^{\circledR}$ for typing strains.

Results: The 90 strains were assigned in 37 phenotypic profiles (I-XXXVII) and the SI was 0.87 . Similarity analysis showed six groups and two singletons: Group 1 (Profiles I, III, VIII, XXXV, XXXVI, and XXXVII, n=35), Group 2 (Profiles XIII, XIV, XVII, and XXVIII, n=4), Group 3 (Profiles II, IX, V, VII, XIX, XXII, XXIII, and XXIV, n=21), Group 4 (Profiles IV, X, XII, XX, XXI, and XXX, n=11), Group 5 (Profiles VI, XI, XXV, XXVI, XXXI, XXXII, XXXIII, and XXXIV, n=11), Group 6 (Profiles XV, XVI, and XXVII, $n=6$ ), Singleton 1 (Profile XXIX, $n=1$ ), and Singleton 2 (Profile XVIII, $n=1$ ). Group 1 was isolated in six areas (A-F) from PWI $(n=27)$, IPS $(n=7)$, and only in one API sample from 2015-2020. These results indicate that PWI used for producing IPS can be the contamination source and this group is an intermittent contaminant over time. Group 2 was isolated from area E in API samples $(n=3)$ in 2017 and from area C in one PTW sample in 2018. Groups 3, 4 and 5 showed $82.63 \%$ of similarity among themselves and were mainly isolated from API samples $(n=30,69.8 \%)$ from area E from 2016-2020. These results indicate that API samples may have the same source of contamination. Group 6 was also mainly isolated from API samples ( $n=5,83.3 \%$ ) from 2017-2018 and from one PTW sample in 2018. Two singletons were isolated from API and IPS samples, respectively.

Conclusion: Evaluation of phenotypic profile of P. aeruginosa strains was considered an interesting tool for microbiological investigation in pharmaceutical industry, since it revealed possible common sources of contamination. As products contaminated with P. aeruginosa are discarded and investigation is necessary to identify the root cause and subsequently the adoption of corrective/preventive actions, Vitek ${ }^{\circledR} 2$ seems to be a fast tool for an initial evaluation. However, other genotyping methods as multi-locus sequence typing are necessary to corroborate this results showing better resolution regarding the strains clonality.

Keywords: Pseudomonas aeruginosa; phenotypic characterization; quality control 